\title{
ДИНАМІКА ЕЛЕКТРОЕНЦЕФАЛОГРАФІЧНИХ ПОКАЗНИКІВ У ПАЦІЄНТІВ, ХВОРИХ НА ДИТЯЧИЙ ЦЕРЕБРАЛЬНИЙ ПАРАЛІЧ, ПІД ВПЛИВОМ КОМПЛЕКСНОГО ЛІКУВАННЯ 3 ВИКОРИСТАННЯМ МЕТОДУ ТРАНСКРАНІАЛЬНОЇ МІКРОПОЛЯРИЗАЦІї
}

\author{
ФК. В. Яценко ${ }^{1,2}$, О. М. Надоненко² \\ ${ }^{1} /$ нститут фізіології імені О. О. Богомольця Національної академії наук України, м. Київ \\ ${ }^{2}$ Неврологічна клініка доктора Яценко, м. Київ
}

РЕЗЮмЕ. Вступ. Особливий інтерес для лікування різних неврологічних розладів, зокрема дитячого церебрального паралічу (ДЦП), викликає такий терапевтичний підхід як мікрополяризація - неінвазивний і безпечний лікувальний метод, що дозволяє змінювати функціональний стан різних ланок ЦНС під дією малого постійного струму.

Мета - визначити за допомогою електроенцефалографії терапевтичну ефективність додавання методу мікрополяризації у комплекс лікувально-профілактичних засобів дітям, хворим на ДЦП.

Матеріали та методи. У ході дослідження було обстежено та комплексно проліковано 33 хворих з різними формами ДЦП. До групи порівняння, яким проводили базисні лікувально-реабілітаційні заходи, увійшло 12 дітей, до основної - 21 дитина, яким на фоні базисної терапії додатково проводили курс мікрополяризації. Транскраніальну мікрополяризацію виконували згідно з розробленими індивідуальними схемами лікування залежно від локалізації патології. За допомогою ЕЕГ оцінювали біоелектричну активність головного мозку в динаміці двічі - до початку лікування та через 3 місяці після закінчення терапевтичного курсу.

Результати. Аналіз електроенцефалограм дітей із ДцП до лікування свідчить про порушення біоелектричної активності мозку різного ступеня вираженості. Після лікування у межах загальної картини формування вікових патернів ЕЕГ спостерігалась спрямована позитивна динаміка фонової біоелектричної активності мозку у 76,2 \% пацієнтів основної групи, порівняно із 25,0 \% дітей групи порівняння. Загальні зміни стосувались стабілізації вікових прекурсорів центрального і альфа-ритмів, а також спостерігалися тенденції до зменшення структурної дезорганізації і дифузного сповільнення ЕЕГ при відсутності збільшення пароксизмальної активності та міжпівкульової асиметрії.

Висновки. Отримані дані свідчать про те, що додавання методу мікрополяризації у комплексне лікування хворих на ДЦП підвищує ефективність лікування, а також може позитивно впливати на клінічний перебіг захворювання.

КЛючОВІ словА: дитячий церебральний параліч; електроенцефалографія; транскраніальна мікрополяризація.

Вступ. Дитячий церебральний параліч (ДЦП) $\epsilon$ однією з найактуальніших проблем сучасної педіатрії та неврології та однією з найчастіших причин дитячої інвалідності. Поширення даної патології у Європі становить від 2 до 3 на 1000 живих новонароджених, в Україні - 2,56 на1000 [1, 2]. Попри велику кількість різноманітних методів лікування ДЦП, досі тривають пошуки медичних технологій для більш ефективного надання допомоги дітям, хворим на церебральний параліч [3].

Особливий інтерес для лікування різних неврологічних розладів становить така терапевтична технологія як мікрополяризація $[4,5]$. Мікрополяризація - це неінвазивний і безпечний лікувальний метод, що дозволяє змінювати функціональний стан різних ланок ЦНС під дією малого постійного струму (до 1 мА) [6-8]. Силу постійного струму, що використовується під час мікрополяризації, можна порівняти з біопотенціалами нейронів, що дозволяє застосовувати цей метод навіть у малюків [9]. Спрямованість впливу мікрополяризації досягається завдяки використанню малих площ (100-600 мм²) електродів. Мікропо- ляризація може бути використана як окремий терапевтичний метод та в поєднанні зі стандартною фізіотерапією для корегування збудливості кори головного мозку і покращення рухової активності у пацієнтів із різними неврологічними розладами, зокрема при ДЦП [10]. Показано, що транскраніальна мікрополяризація (ТМП) інтенсивністю 1 мА не спричиняє патологічних осциляцій і епілептиформної активності у дітей, тому може бути використана в педіатричній практиці як метод лікування [11].

Незважаючи на появу нових методів реєстрації, ідентифікації та відображення біоелектричних потенціалів головного мозку, електроенцефалографія (ЕЕГ) залишається одним із основних та найінформативніших методів об'єктивної оцінки функціонального стану ЦНС, особливо у пацієнтів дитячого віку [12]. ЕЕГ відображає не тільки функціональний стан кори великих півкуль, а й складні кірково-підкіркові взаємозв'язки [13]. Цей метод рекомендований Міжнародною та Американською асоціаціями нейрофізіологів для клінічного використання у хворих на ДЦП [3]. На 
Огляди літератури, оригінальні дослідження, погляд на проблему

EЕГ пацієнтів із церебральним паралічем оптимальне співвідношення активуючих і гальмівних впливів порушено завдяки гіперактивації підкіркових мозкових структур і зниженню гальмівного впливу на них кори великих півкуль [14]. Відомо, що на картину ЕЕГ і її спектри основний вплив має аферентна активність, що пов'язана з різного роду сенсорними впливами, переважно з руховою діяльністю [15]. Можна припустити, що у хворих на ДЦП у рисунку біоелектричної активності насамперед відображається фонова аферентація, яка обумовлена патологічним руховим стереотипом.

Мета дослідження - визначити за допомогою електроенцефалографії терапевтичну ефективність додавання методу мікрополяризації у комплекс лікувально-профілактичних засобів дітям, хворим на церебральний параліч.

Матеріал і методи дослідження. Робота виконувалася на базі Неврологічної клініки доктора Яценко (м. Київ). У ході дослідження було обстежено та комплексно проліковано 33 хворих віком від 2 до 12 років з різними формами ДцП. Дітей було поділено на дві рандомізовані за основними параметрами (стать і вік) групи. До першої групи (група порівняння), яким проводили базисні лікувально-реабілітаційні заходи, увійшли 12 дітей, до другої (основної) групи - 21 дитина, якій на фоні базисної терапії додатково проводили курс транскраніальної мікрополяризації (ТМП).

Базисна терапія включала традиційний комплекс лікувально-реабілітаційних заходів, які комбінувались між собою залежно від індивідуальних потреб пацієнта: кінезіотейпування; біомеханічна стимуляція м'язів; педагогічна та логопедична корекція; масаж та лікувальна фізкультура.

Перед початком курсу лікування дітям проводили клінічне обстеження: збір скарг за загальноприйнятою методикою, вивчення анамнезу, соматоневрологічне обстеження, інструментально-функціональну діагностику. Комплексне обстеження дітей також проводили суміжні спеціалісти (логопед, психолог-дефектолог, реабілітолог та ін.) за загальноприйнятими методиками.

Для встановлення діагнозу дитячого цере6рального паралічу у нашій роботі використовували клінічну класифікацію ДцП [16]. Найбільшу частку становили пацієнти зі спастичною диплегі$є ю-36 \%$ в основній групі та $41 \%$ у контрольній групі; з подвійною геміплегією було 30 \% (у основній групі - 12 \%) пацієнтів; з геміплегічною (геміпаретичною) формою - 19 \% (26\%); з атонічноастатичною формою - $13 \%$ (18\%) та з гіперкінетичною формою - 2 \% (3 \%) відповідно.

Транскраніальну мікрополяризацію виконували за допомогою сертифікованого апарату для мікрополяризації "Реамед-Полярис» (Санкт-Петербург, Росія). Електроди розташовували на шкірі голови згідно з розробленими індивідуальними схемами лікування. Курс лікування складався з 10 щоденних 40-хвилинних сеансів.

За допомогою електроенцефалографії (ЕЕГ) оцінювали біоелектричну активність головного мозку в динаміці двічі - до початку лікування та через 3 місяці після закінчення терапевтичного курсу. Реєстрацію ЕЕГ здійснювали на енцефалографі ДX-500 (DX-sistems, Україна, м. Харків) за стандартною методикою запису біоелектричних потенціалів головного мозку з проведенням функціональних проб (відкривання і закривання очей, ритмічна фотостимуляція (ФС), гіпервентиляція (ГВ)). Розміщення електродів здійснювали за Міжнародною системою 10-20 при скальповій референції в проміжку Fz-Cz. Катамнестичне спостереження після проведеної терапії тривало від 1 до 2 років.

Підтвердження терапевтичної ефективності комплексного методу лікування з використанням транскраніальної мікрополяризації в основній групі відносно групи порівняння здійснювали методом варіаційної статистики. Порівняння середніх значень досліджуваних показників здійснювали за допомогою t-критерію Стьюдента при нормальному розподілі показників. Відповідність закону нормального розподілу ознак перевіряли з використанням критерію Шапіро-Уїлка. Статистично значущими вважали відмінності при $р<0,05$.

Результати й обговорення. Для оцінки ефективності проведеної комплексної терапії із курсом ТМП використовували дані електроенцефалографічного дослідження. ЕЕГ оцінювали відповідно до класифікації Е. А. Жирмунської [13] з огляду на тенденції формування варіантів ЕЕГ у дитячому віці [17].

За формалізованою оцінкою реєстрували такі варіанти біоелектричної активності головного мозку дітей, хворих на ДЦП: організований, дезорганізований з альфа-ритмом і дезорганізований без альфа-ритму, десинхронний, гіперсинхронний, епілептична активність та міжпівкульова асиметрія. Загальну ЕЕГ оцінювали за рівнем структурної дезорганізації ЕЕГ, міжпівукульової асиметрії та пароксизмальної активності.

При візуальному аналізі ЕЕГ визначали стан альфа-ритму (домінантність, стабільність, асиметрію, реактивність, зональність, модуляторність, поліморфність), частоту і амплітуду альфа- і центрального ритмів, виразність повільнохвильової і бета-активності. Визначали стан синхронізації повільнохвильової активності в фоновій ЕЕГ і при функціональних пробах.

За допомогою спектрального аналізу визначали щільну потужність основних частотних діа- 
Огляди літератури, оригінальні дослідження, погляд на проблему

пазонів спектра ЕЕГ (дельта-, тета-, альфа-, бетаритмів). Спектральний аналіз альфа-активності в потиличних і центральних відведеннях важливий у динамічному спостереженні за сенсорнозалежними складовими альфа-діапазону вікової ЕЕГ (альфа- і мю-ритмів) [18].

Аналіз електроенцефалограм дітей із ДцП до лікування свідчить про порушення біоелектричної активності мозку різного ступеня виразності.

У результаті проведеного ЕЕГ дослідження були отримані дані, що представлені у таблиці 1.

У межах загальної картини формування вікових патернів ЕЕГ спостерігали спрямовану позитивну динаміку фонової біоелектричної активності мозку у 76,2 \% пацієнтів основної групи, порівняно із $25,0 \%$ дітей у групі порівняння (табл. 1). Загальні зміни стосувались стабілізації вікових прекурсорів центрального і альфа-ритмів та мали тенденції до зменшення структурної дезорганізації і дифузного сповільнення ЕЕГ при відсутності збільшення пароксизмальної активності та міжпівкульової асиметрії.

Найзначимішу динаміку спостерігали у групі дітей з дезорганізацією ЕЕГ і збереженим альфаритмом (у 66,7 \% пацієнтів основної групи, порівняно із 40,0 \% дітей у групі порівняння): основним критерієм було посилення амплітуди і спектральної потужності альфа-ритму і реактивності під час відкривання очей, реакції засвоєння ФС, посилення зональної предомінатності і модуляторності альфа-ритму (табл. 1).

Позитивну динаміку спостерігали у дітей з дезорганізацією ЕЕГ без альфа-ритму після прове- деного лікування із застосуванням ТМП (у 60,0 \% пацієнтів основної групи). Зміни патерну вираженої дезорганізації ЕЕГ з редукцією альфа- і центрального ритмів мали тенденції до зменшення потужності повільноскадових у потиличних і скроневих ділянках, посилення синхронізації і потужності тета-діапазону в центрально-тім'янопотиличній ділянці. Мало місце зменшення загостреної дизритмії в лобно-центральних і скроневих відділах.

Десинхронний варіант ЕЕГ з дифузним сповільненням переважно низькоамплітудної активності був мало змінний (25 \% у дітей основної групи), спостерігалися тенденції до підсилення тетадіапазону в центральних відділах, фрагментарне підсилення альфа-активності в центральних і потиличних відділах пацієнта (див. табл. 1). У пацієнтів групи порівняння не спостерігали позитивних змін біоелектричної активності головного мозку з десинхронним варіантом ЕЕГ.

Також виражену позитивну динаміку спостерігали після проведеного лікування із застосуванням ТМП у дітей із гіперсинхронним патерном ЕЕГ (100\%, порівняно із 33,3 \% дітей у групі порівняння) (табл. 1). Динаміка стабілізації альфаритму пов'язана з формуванням центрального ритму, зменшенням потужності дифузної синхронізації і повільної активності в лобно-скроневих відділах.

Під час аналізу ЕЕГ також оцінювали виразність змін: легкі (з ізольованими або регіональними змінами основних прекурсорів ритмічної ЕЕГ

Таблиця 1. Динаміка розподілу патернів ЕЕГ у пацієнтів із ДЦП обох груп спостереження під впливом проведеного лікування

\begin{tabular}{|c|c|c|c|c|c|c|}
\hline \multirow{3}{*}{$\begin{array}{l}\text { Патерни ЕЕГ } \\
\text { Організований }\end{array}$} & \multicolumn{3}{|c|}{$\begin{array}{l}\text { Група порівняння } \\
\text { (12 пацієнтів) }\end{array}$} & \multicolumn{3}{|c|}{$\begin{array}{l}\text { Основна група } \\
\text { (21 пацієнт) }\end{array}$} \\
\hline & \multirow{2}{*}{$\begin{array}{c}\begin{array}{c}\text { до лікування, } \\
\text { кількість } \\
\text { дітей }\end{array} \\
-\end{array}$} & \multicolumn{2}{|c|}{$\begin{array}{c}\text { після лікування, } \\
\text { кількість дітей, } \\
\text { «+» означає } \\
\text { кількість дітей } \\
\text { з позитивною } \\
\text { динамікою } \\
\end{array}$} & \multirow{2}{*}{$\begin{array}{c}\begin{array}{c}\text { до лікування, } \\
\text { кількість } \\
\text { дітей }\end{array} \\
-\end{array}$} & \multicolumn{2}{|c|}{$\begin{array}{c}\text { після лікування, } \\
\text { кількість дітей, «+» } \\
\text { означає кількість } \\
\text { дітей з позитивною } \\
\text { динамікою }\end{array}$} \\
\hline & & - & - & & - & - \\
\hline $\begin{array}{l}\text { Дезорганізований з альфа- } \\
\text { ритмом }\end{array}$ & $5 / 12$ & $\begin{array}{c}5 / 12 \\
(+2 / 5)\end{array}$ & $40,0 \%$ & $9 / 21$ & $\begin{array}{c}9 / 21 \\
(+6 / 9)\end{array}$ & $66,7 \%$ \\
\hline $\begin{array}{l}\text { Дезорганізований без альфа- } \\
\text { ритму }\end{array}$ & $2 / 12$ & $2 / 12$ & - & $5 / 21$ & $\begin{array}{c}5 / 21 \\
(+3 / 5) \\
\end{array}$ & $60,0 \%$ \\
\hline Десинхронний & $2 / 12$ & $2 / 12$ & - & $4 / 21$ & $\begin{array}{l}4 / 12 \\
(+1 / 4)\end{array}$ & $25,0 \%$ \\
\hline Гіперсинхронний & $3 / 12$ & $\begin{array}{c}3 / 12 \\
(+1 / 3)\end{array}$ & $33,3 \%$ & $3 / 21$ & $\begin{array}{l}3 / 21 \\
(+3 / 3)\end{array}$ & $100 \%$ \\
\hline Епілептична активність & $2 / 12$ & $2 / 12$ & - & $7 / 21$ & $7 / 21$ & - \\
\hline Міжпівкульова асиметрія & $6 / 12$ & $6 / 12$ & - & $12 / 21$ & $\begin{array}{c}12 / 21 \\
(+3 / 12)\end{array}$ & $25,0 \%$ \\
\hline $\begin{array}{l}\text { Всього пацієнтів із позитивною } \\
\text { динамікою }\end{array}$ & & $+3 / 12$ & $25,0 \%$ & & $+16 / 21$ & $76,2 \%$ \\
\hline
\end{tabular}


Огляди літератури, оригінальні дослідження, погляд на проблему

альфа- і центрального ритму), помірні (з частотно-просторовою дезорганізацією ЕЕГ, пароксизмальною активністю і ознаками нейрофізіологічної незрілості) та виражені (з частотною перебудовою структури ЕЕГ з дифузним і регіональним сповільненням, патологічними феноменами, ознаками вираженої затримки електроґенезу).

Аналіз даних ЕЕГ обстеження у дітей основної групи з легкими дифузними змінами зі збереженням структурно-просторової організації в динаміці показав стабілізацію вікових прекурсорів ритмічної ЕЕГ, підсилення альфа-ритму, зменшення синхронізації центрального ритму.

У дітей основної групи із помірними дифузними змінами регуляторного характеру з ознаками нейрофізіологічної незрілості (у вигляді підсилення потужності повільнохвильової складової спектра ЕЕГ, нестабільності і сповільнення альфаритму, екзальтації центрального мю-ритму, підсилення спалахової синхронізуючої активності) в динаміці спостерігали покращення структурної організації і реактивності альфа- і центрального ритмів після комплексного лікування із застосуванням ТМП. Серед переважаючих загальномозкових змін і локальних акцентів з помірною міжпівкульовою асиметрією і епілептиформною активістю не спостерігалося підсилення вогнищевої патологічної активності, спалахів білатеральної синхронізації в фоновій ЕЕГ і при пробах ФС і ГВ.

У дітей основної групи з вираженими загальномозковими змінами і нейрофізіологічною незрілістю спостерігали структурну перебудову вікової ЕЕГ з домінуванням повільнохвильової активності і редукцією вікових прекурсорів центрального і альфа-ритму, спалахами дифузної синхронізації і локальними пароксизмальними змінами ЕЕГ. Пароксизмальна активність характеризувалася білатерально-синхронними спалахами тета-, дельта-хвиль амплітудою більше 120 мкВ (у однієї дитини) і наявністю комплексів гостра і пік-повільна хвиля, білатеральною синхронізацією епіактивності амплітудою вище фону (у 2 дітей).

У динаміці в дітей на фоні комплексного лікування з використанням транскраніальної мікрополяризації на першому етапі спостерігали різнонаправлені зміни, які згодом мали ознаки стабілізації вікових прекурсорів ритмічної активності у формуванні відповідних вікових патернів ЕЕГ. У структурі біоелектричної активності головного мозку у дітей основної групи спостерігали підсилення індексу потужності альфа-ритму (з 7,7 до $12,8)$ і підсилення центрального мю-ритму (з 4,5 до 8,9), ймовірно, компенсаторного характеру. Також у дітей основної групи після проведеного лікування із застосуванням ТМП знижувалися синхронізуючі впливи серединних структур мозку (зменшувався індекс спалахової активності з 17 до 10,6), тоді як у групі порівняння така позитивна динаміка не спостерігалася.

Результати спектрально-амплітудного математичного перетворення аналогової ЕЕГ основної групи та групи порівняння (результати Фур'єаналізу вихідних даних ЕЕГ), призначених для динамічного спостереження за спектральними потужностями визначених частотних діапазонів (ритмічні складові ЕЕГ), представлені в таблиці 2.

У дітей основної групи спектральна щільність потужності (СЩП) альфа-ритму статистично вірогідно збільшилася на 24,1 \%, тоді як у групі порівняння наростання СЩП альфа-ритму склало лише $11,4 \%$.

У пацієнтів обох груп спостереження виявлено статистично вірогідне збільшення СЩп бетадіапазону: в основній групі цей показник становив $26,9 \%$, у групі порівняння $-17,3 \%$.

Повільнохвильова частина спектра ЕЕГ під впливом проведеного лікування також мала позитивну динаміку у вигляді зменшення потужності. Після комплексного лікування із використанням мікрополяризації у пацієнтів з дцП спек-

Таблиця 2. Результати Фур'є-аналізу даних електроенцефалограм пацієнтів із ДцП обох груп спостереження під впливом проведеного лікування

\begin{tabular}{|l|c|c|c|c|}
\hline \multirow{2}{*}{$\begin{array}{c}\text { Група порівняння, } \\
\mathrm{n}=12\end{array}$} & \multicolumn{4}{|c|}{ Діапазон, мкВ $(\mathrm{M} \pm \mathrm{m})$} \\
\cline { 2 - 5 } & альфа & 6 дета & дельта & тета \\
\hline До лікування & $43,7 \pm$ & $15,8 \pm$ & $197,3 \pm$ & $171,2 \pm$ \\
\hline Після лікування & $49,3 \pm$ & $19,1 \pm$ & $-10,2$ & $-13,4$ \\
\hline$\Delta \%$ & $+11,4$ & $+17,3$ & дельта & тета \\
\hline Основна група, $\mathrm{n}=21$ & альфа & $6 е т а ~$ & $195,7 \pm$ & $198,2 \pm$ \\
\hline До лікування & $53,1 \pm$ & $14,7 \pm$ & $128,4 \pm$ & $128,1 \pm$ \\
\hline Після лікування & $70,0 \pm$ & $20,1 \pm$ & $-34,4$ & $-35,4$ \\
\hline$\Delta \%$ & $+24,1$ & $+26,9$ & & \\
\hline
\end{tabular}

Примітка. * - статистично вірогідні відмінності (p<0,05), n - кількість досліджених осіб у групі. 
Огляди літератури, оригінальні дослідження, погляд на проблему

тральна щільність потужності дельта-ритму на ЕЕГ статистично вірогідно знизилась на 34,4 \%, а СЩП тета-хвиль - на 35,4%. У пацієнтів групи порівняння не спостерігали статистично вірогідної динаміки зменшення СЩП цих діапазонів повільнохвильової частини спектра.

Результати Фур'є-аналізу даних ЕЕГ у пацієнтів з ДЦП підтверджують більшу терапевтичну ефективність комплексного методу лікування $з$ використанням мікрополяризації, порівняно $з$ традиційними лікувально-реабілітаційними заходами.

Висновки. Аналіз даних електроенцефалографічного дослідження у пацієнтів з ДЦП групи порівняння та основної до і після лікування свідчить про те, що у хворих основної групи, в комплексне лікування яких додавалася транскраніальна мікрополяризація, спостерігалася вираженіша позитивна динаміка параметрів ЕЕГ. Такі зміни у дітей з церебральним паралічем після комплексного лікування із додаванням методу ТМП свідчать про позитивний розвиток функціональної організації головного мозку, що створює сприятливіші умови для реалізації психофізіологічних функцій у даній групі пацієнтів. Отримані дані дають підстави стверджувати, що включення до комплексного лікування дітей, хворих на ДЦП, методу транскраніальної мікрополяризації збільшує ефективність їх лікування та позитивно впливає на клінічний перебіг захворювання.

Перспективи подальших досліджень. Планується дослідження впливу комплексного лікування із застосуванням транскраніальної мікрополяризації на стан нервово-м'язового апарату пацієнтів, хворих на ДЦП, із використанням методу електронейроміографії.

\section{ЛITEPATУРA}

1. Krägeloh-Mann I. Cerebral palsy update / I. Krägeloh-Mann, C. Cans // Brain Dev. - 2009. - Vol. 31. - P. 537-544.

2. Статистичний бюлетень «Заклади охорони здоров'я та захворюваність населення України у 2010 році» / Держкомстат України. - К., 2011. - 96 с.

3. Основи медико-соціальної реабілітації дітей з органічними ураженнями нервової системи : навч.метод. посібник / за ред. Мартинюка В. Ю., Зінченко С. М. - К. : Інтермед, 2005.

4. Шелякин А. М. Микрополяризация мозга. Теоретические и практические аспекты / А. М. Шелякин, Г. Н. Пономаренко. - СПб. : Балтика, 2006.

5. The effects of anodal transcranial direct current stimulation and patterned electrical stimulation on spinal inhibitory interneurons and motor function in patients with spinal cord injury / T. Yamaguchi, T. Fujiwara, Y. Tsai [et al.] // Exp. Brain Res. - 2016. - Vol. 234. - P. 1469-1478.

6. A systematic review of the clinical efficacy of transcranial direct current stimulation (tDCS) in psychiatric disorders / M. Kekic, E. Boysen, I. C. Campbell [et al.] // J. Psychiatr. Res. - 2016. - Vol. 74. - P. 70-86.

7. Exploring the efficacy of a 5-day course of transcranial direct current stimulation (TDCS) on depression and memory function in patients with wellcontrolled temporal lobe epilepsy / A. Liu, A. Bryant, A. Jefferson [et al.] // Epilepsy Behav. - 2016. - Vol. 55. - P. 11-20.

8. Effect of transcranial direct current stimulation over the primary motor cortex on cerebral blood flow: a time course study using near-infrared spectroscopy / H. Takai, A. Tsubaki, K. Sugawara [et al.] // Adv. Exp. Med. Biol. - 2016. - Vol. 876. - P. 335-341.

9. Шелякин А. М. Микрополяризационная терапия в детской неврологии (практическое руководство) / А. М. Шелякин, И. Г. Преображенская, О. В. Богданов. - M., 2008.

10. Synergistic effect of combined transcranial direct current stimulation/constraint-induced movement therapy in children and young adults with hemiparesis: study protocol / B. Gillick, J. Menk, B. Mueller [et al.] // BMC Pediatr. - 2015. - Vol. 15. - P. 178.

11. Ten minutes of $1 \mathrm{~mA}$ transcranial direct current stimulation was well tolerated by children and adolescents: Self-reports and resting state EEG analysis / V. Moliadze, S. Andreas, E. Lyzhko [et al.] // Brain Res. Bull. - 2015. Vol. 119. - P. 25-33.

12. Olbrich S. Personalized medicine: review and perspectives of promising baseline EEG biomarkers in major depressive disorder and attention deficit hyperactivity disorder / S. Olbrich, R. V. Dinteren, M. Arns // Neuropsychobiology. - 2016. - Vol. 72. - P. 229-240.

13. Жирмунская Е. А. Система описания и классификация энцефалограмм человека / Е. А. Жирмунская, В. С. Лосев. - М. : Наука, 1994.

14. Шейнкман О. Г. Особенности функционального состояния мозга недоношенных детей грудного и раннего возраста с перинатальной энцефалопатией и детским церебральным параличом // Журнал неврологии и психиатрии им. С. С. Корсакова. - 2003. - № 6. - C. 37-42.

15. Pfurtscheller G. Rhythmic EEG activities and cortical functioning / G. Pfurtscheller. - Amsterdam: Elsevier / North-Holland Biomedical Press, 1980.

16. Семенова К. А. Методические рекомендации по применению рабочей классификации детского церебрального пар алича / К. А. Семенова. - М., 1973.

17. Новинская Н. Л. Сопоставление клинических, энцефалографических показателей у детей с различными видами интеллектуальной недостаточности / Н. Л. Новинская, Е. В. Горбачевская // Неврология и психиатрия. - 1980. - № 7. - С. 17-23.

18. Фарбер Д. А. Гетерогенность и возрастная динамика а-ритма электроэнцефалограммы / Д. А. Фарбер, В. Ю. Вильдавский // Физиология человека. - 1996. - № 5. - С. 52-55. 
Огляди літератури, оригінальні дослідження, погляд на проблему

\section{REFERENCES}

1. Krägeloh-Mann, I., \& Cans, C. (2009). Cerebral palsy update. Brain and Development, 31 (7), 537-544. doi:10.1016/j.braindev.2009.03.009

2. Statistchnyi biuleten "Zaklady okhorony zdorovya ta zakhvoryuvanist naselennia Ukrainy u 2010 rotsi» [Statistical Bulletin "Healthcare and morbidity of the population of Ukraine in 2010"]. (2011). Kyiv. [in Ukrainian].

3. Martyniuk, V.Yu., \& Zinchenko, S.M. (2005). Osnovy medyko-sotsialnoi reabilitatsii ditey z orhanichnymy urazhenniamy nervovoi systemy [Fundamentals of medical and social rehabilitation of children with organic lesions of the nervous system]. Kyiv: Intermed. [in Ukrainian]

4. Shelyakyn, A. M., \& Ponomarenko, H. N. (2006). Mikropolyarizatsyya mozga. Teoreticheskye i prakticheskie aspekty [Direct current stimulation of the brain. Theoretical and practical aspects]. Saint-Petersburg: Baltika [in Russian].

5. Yamaguchi, T., Fujiwara, T., Tsai, Y., Tang, S. Kawakami, M., Mizuno, K., ... Liu, M. (2016). The effects of anodal transcranial direct current stimulation and patterned electrical stimulation on spinal inhibitory interneurons and motor function in patients with spinal cord injury. Experimental Brain Research, 234 (6), 14691478. doi:10.1007/s00221-016-4561-4

6. Kekic, M., Boysen, E., Campbell, I. C., \& Schmidt, U. (2016). A systematic review of the clinical efficacy of transcranial direct current stimulation (tDCS) in psychiatric disorders. Journal of Psychiatric Research, 74, 70-86. doi:10.1016/j.jpsychires.2015.12.018

7. Liu, A., Bryant, A., Jefferson, A., Friedman, D., Minhas, P., Barnard, S., ... Schachter, S. (2016). Exploring the efficacy of a 5-day course of transcranial direct current stimulation (TDCS) on depression and memory function in patients with well-controlled temporal lobe epilepsy. Epilepsy \& Behavior, 55, 11-20. doi:10.1016/j. yebeh.2015.10.032

8. Takai, H., Tsubaki, A., Sugawara, K., Miyaguchi, S., Oyanagi, K., Matsumoto, T., ... Yamamoto, N. (2016). Effect of transcranial direct current stimulation over the primary motor cortex on cerebral blood flow: a time course study using near-infrared spectroscopy. Advances in Experimental Medicine and Biology, 876, 335-341. doi:10.1007/978-1-4939-3023-4_42

9. Shelyakyn, A.M., Preobrazhenskaya, Y.H., Bogdanov, O.V. (2008). Mikropolyarizatsionnaya terapiya $v$ detskoy nevrologii (prakticheskoe rukovodstvo) [Direct current stimulation therapy in pediatric neurology (Practical guidance)]. Moscow. [in Russian]

10. Gillick, B., Menk, J., Mueller, B., Meekins, G., Krach, L. E., Feyma, T., \& Rudser, K. (2015). Synergistic effect of combined transcranial direct current stimulation/ constraint-induced movement therapy in children and young adults with hemiparesis: study protocol. BMC Pediatrics, 15 (1), 178. doi:10.1186/s12887-015-0498-1

11. Moliadze, V., Andreas, S., Lyzhko, E., Schmanke, T., Gurashvili, T., Freitag, C. M., \& Siniatchkin, M. (2015). Ten minutes of $1 \mathrm{~mA}$ transcranial direct current stimulation was well tolerated by children and adolescents: Self-reports and resting state EEG analysis. Brain Research Bulletin, 119, 25-33. doi:10.1016/j.brainresbull.2015.09.011

12. Olbrich, S., Dinteren, R. V., \& Arns, M. (2016). Personalized medicine: review and perspectives of promising baseline EEG biomarkers in major depressive disorder and attention deficit hyperactivity disorder. Neuropsychobiology, 72 (3-4), 229-240. doi:10.1159/000437435

13. Zhyrmunskaya, E.A., Losev, V.S. (1994). Sistema opisaniya $i$ klassifikatsiya entsefalogramm cheloveka [The system of description and classification of human encephalograms]. Moscow: Nauka. [in Russian]

14. Sheynkman, O.H. (2003). Osobennosti funktsionalnogo sostoyaniya mozga nedonoshennyh detey grudnogo i rannego vozrasta s perinatalnoy entsefalopatiey i detskim tserebralnym paralichom [Features of the functional state of the brain of preterm infants and young children with perinatal encephalopathy and cerebral palsy]. Zhurnal nevrologii $i$ psihiatrii im. S.S. Korsakova - Journal of Neurology and Psychiatry by S.S. Korsakov, 6, 37-42. [in Russian].

15. Pfurtscheller, G. (1980). Rhythmic EEG activities and cortical functioning. Amsterdam: Elsevier / NorthHolland Biomedical Press.

16. Semenova, K.A. (1973). Metodicheskie rekomendatsii po primeneniyu rabochey klassifikatsi detskogo tserebralnogo paralicha [Methodical recommendations on the application of the working classification of cerebral palsy]. Moscow [in Russian].

17. Novynskaya, N.L., Horbachevskaya, E.V. (1980). Sopostavlenie klinicheskikh, entsefalograficheskikh pokazateley u detey s razlychnymi vidami intellektualnoy nedostatochnosti [Comparison of clinical, encephalographic indicators in children with various types of intellectual insufficiency]. Nevrologiya i psikhiatriya Neurology and Psychiatry, 7, 17-23 [in Russian].

18. Farber, D.A., Vyldavskyy, V.Yu. (1996). Geterogennost i vozrastnaya dinamika a-ritma elektroentsefalogrammy [Heterogeneity and age dynamics of the a-rhythm of the electroencephalogram]. Fiziologiya cheloveka - Physiology of the Man, 5, 52-55 [in Russian]. 


\title{
Огляди літератури, оригінальні дослідження, погляд на проблему \\ ДИНАМИКА ЭЛЕКТРОЭНЦЕФАЛОГРАФИЧЕСКИХ ПОКАЗАТЕЛЕЙ У ПАЦИЕНТОВ С ДЕТСКИМ ЦЕРЕБРАЛЬНЫМ ПАРАЛИЧОМ ПОД ВЛИЯНИЕМ КОМПЛЕКСНОГО ЛЕЧЕНИЯ С ИСПОЛЬЗОВАНИЕМ МЕТОДА ТРАНСКРАНИАЛЬНОЙ МИКРОПОЛЯРИЗАЦИИ
}

\author{
ОЕ. В. Яценко ${ }^{1,2}$, А. Н. Надоненко 2 \\ ${ }^{1}$ Институт физиологии имени А. А. Богомольца Национальной академии наук Украины, г. Киев \\ ${ }^{2}$ Неврологическая клиника доктора Яценко, г. Киев
}

РЕзЮМЕ. Введение. Особый интерес для лечения различных неврологических расстройств, в частности детского церебрального паралича (ДЦП), вызывает такой терапевтический подход, как микрополяризация неинвазивный и безопасный лечебный метод, позволяющий изменять функциональное состояние различных звеньев ЦНС под действием малого постоянного тока.

Цель - определить с помощью электроэнцефалографии терапевтическую эффективность добавления метода микрополяризации в комплекс лечебно-профилактических мероприятий детям с ДЦП.

Материалы и методы. В ходе исследования было обследовано и комплексно пролечено 33 больных с различными формами ДЦП. В группу сравнения вошло 12 детей, которым проводили базисные лечебно-реабилитационные мероприятия, в основную-21 ребенок, которым на фоне базисной терапии дополнительно проводили курс микрополяризации. Транскраниальную микрополяризацию выполняли в соответствии с разработанными индивидуальными схемами лечения в зависимости от локализации патологии. С помощью ЭЭГ оценивали биоэлектрическую активность головного мозга в динамике дважды - до начала лечения и через 3 месяца после окончания курса терапии.

Результаты. Анализ электроэнцефалограмм детей с ДЦП до лечения свидетельствовал о нарушении биоэлектрической активности мозга различной степени выраженности. После лечения в рамках общей картины формирования возрастных паттернов ЭЭГ наблюдалась положительная динамика фоновой биоэлектрической активности мозга у 76,2 \% пациентов основной группы, в сравнении с 25,0 \% детей в группе сравнения. Общие изменения касались стабилизации возрастных прекурсоров центрального и альфа-ритмов, а также наблюдались тенденции к уменьшению структурной дезорганизации и диффузного замедления ЭЭГ при отсутствии увеличения пароксизмальной активности и межполушарной асимметрии.

Выводы. Полученные данные свидетельствуют о том, что добавление метода микрополяризации в комплекс лечения больных ДЦП повышает эффективность лечения, а также может положительно влиять на клиническое течение заболевания.

КЛючЕВыЕ СЛОВА: детский церебральный параліч; электроэнцефалография; транскраниальная микрополяризация.

\section{DYNAMICS OF ELECTROENCEPHALOGRAPHIC PARAMETERS IN PATIENTS WITH CEREBRAL PALSY AFTER COMBINED TREATMENT WITH TRANSCRANIAL DIRECT CURRENT STIMULATION}

\author{
@K. V. Yatsenko ${ }^{1,2}$, O. M. Nadonenko ${ }^{2}$ \\ 'O. Bohomolets Institute of Physiology of NAS of Ukraine, Kyiv \\ ${ }^{2}$ Doctor Yatsenko Neurological Clinic of Kyiv
}

SUMMARY. Introduction. Direct current stimulation (DCS) is of interest for the treatment of various neurological disorders, including cerebral palsy (CP). DCS is a noninvasive and safe therapeutic method which modifies the functional status of various parts of the CNS under the influence of small direct current.

The aim of the study was to determine the therapeutic efficacy of DCS in combined treatment of children with CP using electroencephalography.

Materials and Methods. 33 patients with various forms of CP were examined and treated. 12 children were included in comparison group who underwent basic treatment, and 21 children-in the main group who underwent basic treatment and DCS. Transcranial DCS was performed according to individual treatment regimens based on the location of pathology. The dynamics of bioelectric activity of brain was evaluated twice using EEG - before treatment and 3 months after the therapeutic course.

Results. Analysis of electroencephalograms of children with CP before treatment showed the disruption of neural activity in a local brain region of varying degrees of severity. After the treatment the positive dynamics of background electrical activity of the brain was observed in $76.2 \%$ of patients in the main group, compared with $25.0 \%$ of children in the comparison group. General changes concerned the age stabilization of central and alpha rhythms precursors and the tendency of reduction of structural disorganization and diffuse slowing of the EEG with the absence of paroxysmal activity and interhemispheric asymmetry was observed.

Conclusions. The data indicate that the addition of DCS in the treatment of patients with CP increases the effectiveness of treatment and may also positively influences on the course of the disease.

KEY WORDS: cerebral palsy; plectroencephalography; transcranial direct current stimulation.

Отримано 25.04.2017 